\title{
GNSS Tabanlı Tektonik Uygulamalar için Çevirim İçi Bir Servis: Tektonik Araçlar
}

\author{
Halil İbrahim SOLAK ${ }^{1 *}$, ibrahim TiRYAKIOĞLU ${ }^{2}$ \\ ${ }^{1}$ Afyon Kocatepe Üniversitesi, Uzaktan Eğitim Meslek Yüksekokulu, Afyonkarahisar. \\ ${ }^{2}$ Afyon Kocatepe Üniversitesi, Mühendislik Fakültesi, Harita Mühendisliği Bölümü, Afyonkarahisar. \\ Sorumlu yazar e-posta: hisolak@aku.edu.trＯRCID ID: http://orcid.org/0000-0001-5286-0369 \\ e-posta: itiryakioglu@aku.edu.tr ORCID ID: http://orcid.org/0000-0002-4954-7109
}

Geliş Tarihi: 01.06.2020 Kabul Tarihi: 26.08 .2020

Öz

GNSS (Global Navigation Satellite System) teknolojisinin gelişmesi ile birlikte haritacılık uygulamaları çeşitlenmiştir. Bunlardan biri GNSS tabanlı tektonik uygulamalardır. GNSS tabanlı bir tektonik uygulama süreci temel olarak ağ planlaması, GNSS gözlemleri, elde edilen verilerin kontrolü, değerlendirmeye hazır hale getirilmesi, değerlendirilmesi ve sonuçların yorumlanması aşamalarından oluşmaktadır. Bu aşamaların uygulanması sırasında el yordamıyla yapılması gereken dosya düzenleme, oluşturma, birleştirme, kalite kontrolü, çeşitli yazılımlar yardımıyla ara kontrol, ara çıktıların üretilmesi, çıktı dosyalarının başka bir yazılımın girdi dosyasına dönüştürülmesi, koordinat dönüşümü gibi uzun zaman alan, bazıları için Linux işletim sistemi gerektiren ve karmaşık olan ara işlemler bulunmaktadır. Bu durum işlem sürecini uzatmakta ve hata olasılığını arttırabilmektedir. Bahsedilen durumlar göz önünde bulundurulduğunda bu sürecin hem çalışma hem de araştırmacılar için bir dezavantaj oluşturduğu değerlendirilmektedir. Bu çalışma kapsamında ilgili alanlarda çalışan tüm araştırmacıların ücretsiz olarak kullanabilmesi için yazarlar tarafından geliştirilen ve Tektonik Araçlar olarak adlandırılan, yukarıda bahsedilen işlemleri pratik olarak gerçekleştirmeye yarayan Python tabanlı çevirim içi bir servis örnek uygulama ile anlatılmıştır.

\section{An Online Service for GNSS-Based Tectonic Applications: Tectonic Tools}

Abstract

Geomatics applications have diversified with the development of GNSS technology and one of them is GNSS-based tectonic applications. A GNSS-based tectonic application process is consists of a network planning, static GNSS observations, control of the data obtained, preparation of data for evaluation,

Keywords

GNSS; Tectonic;

Python; Flask; Tectonic Tools evaluation of data and interpretation of the results. During the application of these stages, there are preparation processes that require a long time, dependent on the operating system and complex like file editing, creating, merging, data quality control, producing intermediate outputs, manually converting output files into the input file of another software, coordinate conversion. This can prolong the process and increase the likelihood of errors. Considering these conditions, it is considered that this process creates a disadvantage for both the study and the researchers. Within the scope of this study, a Python-based online service, which is developed by the authors and called as Tectonic Tools for practicing all the researchers working in the related fields, is explained with a sample application.

(C) Afyon Kocatepe Üniversitesi

\section{Giriş}

GNSS teknolojisinde meydana gelen gelişmelerle birlikte uydu bazlı konum belirleme doğruluğu, kullanılan ölçü yöntemine bağlı olarak $\mathrm{mm}$ mertebesine ulaşmıştır. Bu durum konum bilgisini üreten, kullanan ve bu bilgiyi, ihtiyaç duyan disiplinlere koordinat, alan, yüzey, ortofoto gibi çeşitli formatlarda altlık olarak sağlayan haritacılık sektörünün faaliyet alanlarının genişlemesine ve ilerlemesine katkıda bulunmuştur. Bu sayede 
tektonik hareketlerin belirlenmesi, harita mühendisliği disiplininin aktif olarak görev aldığı ve daha çok yöneldiği faaliyet alanlarından biri olmuştur.

Belirli bir bölgede gerçekleştirilen periyodik GNSS gözlemleri ile birlikte büyük ölçekli levhalara göre rölatif olarak belirlenen hızlar ile tektonik hareketleri belirlemek mümkün hale gelmiştir. Yapılan çalışmalarda elde edilmek istenen sonucun, büyük ölçekteki levhalar referans alınarak küçük ölçekteki levhaların hareketlerinin belirlenmesi olduğu düşünüldüğünde ve elde edilen verilerin doğruluk ölçütüne bakıldığında, jeodezik uzay teknikleri ve özellikle GNSS tekniğinin levha hareketlerinin belirlenmesi için en uygun teknik olduğu yapılan çok sayıda çalışma ile belirlenmiştir (Yavaşoğlu 2003, Tiryakioğlu vd. 2010, Tiryakioğlu vd. 2017).

GNSS gözlemleri ile tektonik hareketlerin belirlenmesi çalışma bölgesi belirlendikten sonra temelde 4 aşama olarak sınıflandırılabilir. Bunlar:

- Ağ planlaması

- GNSS gözlemleri

- Verilerin hazırlanması ve değerlendirilmesi

- Sonuçların yorumlanması

olarak ifade edilebilir.

\section{Ağ planlaması}

Ağ planlaması, yapılan çalışmanın amacına ulaşması, beklenen sonuçlara yönelik çıktıların elde edilmesi, arazi çalışması sırasında zamandan ve bütçeden tasarruf edebilme açısından oldukça önemlidir. İyi bir ağ planlaması için iyi bir altlığa intiyaç duyulmaktadır. Günümüzde altlık için MTA (Maden Tetkik Arama) diri fay haritaları, HGM Küre ve Google Earth uygulamaları kullanılmaktadır. Tektonik hareketlerin belirlenmesi amacıyla kurulacak olan ağlarda noktaların faya ve birbirlerine göre konumu, sonuçların daha anlamlı ve yorumlanabilir olması açısından büyük önem arz etmektedir. Bu nedenle bölge tektoniği ile ilgili daha sağlıklı ve homojen sonuçlara ulaşabilmek için ağ planlaması sırasında disiplinler arası bir çalışma ile bölge blok sınırları, jeolojik yapı ve ölçme tekniği, bölgenin topografyası, fayın türü ve yönü, noktaların birbirlerine göre konumları mutlaka göz önünde bulundurulmalıdır (Solak 2015).

Ağ planlaması yapılırken seçilen çalışma bölgesinde farklı kurumlar tarafından tesis edilmiş, geçmişe yönelik tesis ölçüsü ya da uzun süreli ölçüsü olan veya sabit istasyon olarak hizmet veren noktaların kullanılması hem maliyet hem de daha az ölçü ile sonuç elde edebilme açısından önemlidir. Bu nedenle Tapu Kadastro Genel Müdürlüğü (TKGM) kontrolündeki Tusaga-Aktif (CORS-TR) ve Harita Genel Müdürlüğü (HGM) kontrolündeki Türkiye Ulusal Temel GPS Ağı'na (TUTGA) ek olarak varsa bölgeye ait GPS/GNSS verisi araştırılmalıdır. Bu konuda ilgili kurum ve kuruluşlarla (TKGM, HGM, Devlet Su Işleri, Belediyeler, Özel sektör vb.) iletişime geçilmeli ve bölgeye ait veriler uygun protokollerle temin edilmelidir.

Tusaga-Aktif ve TUTGA verileri düzenli olarak ilgili kurumlar tarafından değerlendirildiği için RINEX (Receiver Independent Exchange Format) yapısına uygundur ve düzenli bir şekilde arşivlenir (GNSS verisi değerlendirme yazılımları RINEX formatını kullanır). Ancak diğer kurum ve kuruluşlardan elde edilen veriler binlerce, düzensiz ve tekrarlı olabilmektedir. Bu durum ağ planlaması öncesi uzun bir veri düzenleme işlemi gerektirmektedir. Bu nedenle ağın kaç noktadan oluşacağı, yeni nokta tesis edilip edilmeyeceği (eğer edilecekse yeni noktaların konumları), hangi noktaların ölçüleceği konularında karar vermek zaman almaktadır. Mevcut noktalara ait ölçü sayısı ve süresi, noktalara ait ölçü bilgileri (ölçüsü olan yıllar, kullanılan alıcı ve anten bilgisi, anten yüksekliği, tesis türü vb.) doğru, hızlı ve düzenli bir biçimde elde edilerek bir altlık üzerinde görüntülenmesi zamandan ve bütçeden tasarruf sağlamakla birlikte daha iyi bir ağ planlamasına olanak sağlamaktadır.

\section{GNSS gözlemleri}

GNSS tekniği ile levha hareketlerinin belirlenmesi amacıyla yapılacak ölçüler ağ kurulduktan sonra 
belirlenen noktalarda uygun ölçü stratejisi ile gerçekleştirilir. Jeodinamik amaçlar için tasarlanmış GNSS ağlarında kabuk deformasyonu çalışmalarından elde edilen GNSS hızları, elastik deformasyon hakkında önemli bilgiler sağlamakta ve tekrarlı jeodezik ölçmelerden gelen bu verilerin analizi, yerkabuğu deformasyonu çalışmalarına ışık tutmaktadır (Özener vd. 2009).

Tektonik ve deformasyon amaçlı kurulan GNSS ağlarında ölçülerden meydana gelen sapmaların belirlenmesi ve ölçüler arası korelasyonun arttırıması amacıyla tekrarlı ve eş zamanlı gözlemler gerçekleştirilir. Mühendislik yapılarındaki deformasyonların ve tektonik hareketlerin belirlenmesi ve izlenmesi çalışmaları için yapılan ölçülerin doğruluğunun yüksek olması gerekmektedir. Bu nedenle bu amaçla kurulan ağlarda gerçekleştirilecek GNSS gözlemleri 4-12 saat arasında ve statik oturum şeklinde gerçekleştirilmelidir (Eckl et al. 2001, Tiryakioğlu vd. 2010). Örnek ölçü stratejisi Çizelge 1'de verilmiştir.

Çizelge 1. Örnek GNSS Ölçü Stratejisi

\begin{tabular}{ll}
\hline Parametre & Değer \\
\hline Ölçü Türü & Statik \\
Oturum sayısı & 2 gün tekrarlı \\
Veri toplama aralığı & $15 \mathrm{sn}$ \\
Ölçü Süresi & Min. 8 saat \\
Uydu yükseklik açısı & $10^{\circ}$ \\
\hline
\end{tabular}

\section{Verilerin hazırlanması ve değerlendirilmesi:}

Gerek çeşitli kurum ve kuruluşlardan elde edilen verilerde, gerekse yeni gerçekleştirilen GNSS gözlemlerine ait RINEX dosyalarında değerlendirme öncesi düzenleme yapılması gereken durumlar meydana gelebilmektedir. Bunlar:

- RINEX kalite kontrolü

- RINEX birleştirme

- RINEX saniye dönüştürme

- RINEX tarih düzeltme

şeklinde ifade edilebilir. GNSS verileri gerekli düzenleme işlemleri yapıldıktan sonra çeşitli yazılımlar (Gamit/GLOBK, Bernese, GIPSY/Oasis, çevirim içi değerlendirme servisleri) yardımıyla değerlendirilir. Değerlendirme sonucunda çalışma bölgesine ait hız ve gerinim alanları üretilir.

\section{Sonuçların yorumlanması}

Değerlendirme işlemi bittikten sonra elde edilen çıktılar yardımıyla (hız, gerinim vb.) literatür bilgileri de göz önünde bulundurularak araştırmacılar tarafından bölge tektoniği hakkında yorum ve analiz sürecine geçilir. Çıktı dosyalarının formatı kullanılan yazılım ya da servise bağlı olmakla birlikte veriler sayısal olarak üretilir. Veri değerlendirme aşamasının sağlıklı olup olmadığını sayısal veriler üzerinden tespit etmek zor ve zaman alıcıdır. $\mathrm{Bu}$ nedenle elde edilen çıktıların görselleştirilmesi, noktaların birbiri ile uyumu ve aykırı noktaların tespiti, değerlendirmede sorun olup olmadığı, güncel depremlerin meydana geldiği noktalar ve sonuçlarla ilişkisi yorumlamalar açısından oldukça önemlidir. Görsel çıktılar yorumlama sürecini hızlandırmakta ve kolaylaştırmaktadır.

Yukarıda bahsedilen işlemlerde kullanılan yazılımların kurulumu ve kullanımı ileri seviye akademik bilgi ve farklı donanımlar gerektirmektedir. Bu durum araştırmacıların (lisans, lisansüstü, akademisyenler) tektonik uygulama sürecini hem uzatmakta hem de hata olasılığını arttırabilmektedir. Bununla birlikte kullanılan ara yazılımların çalıştığı işletim sistemine bağlı olarak bilgisayarlar arası dosya taşıma gerektirebilmektedir. Bahsedilen durumlar göz önünde bulundurulduğunda bu sürecin hem çalışma hem de çalışan kişi için bir dezavantaj oluşturduğu ve bu işlemler için kolaylık sağlayacak bir sisteme ihtiyaç olduğu değerlendirilmiştir.

Bu çalışma kapsamında ilgili alanlarda çalışan tüm araştırmacıların ücretsiz olarak kullanabilmesi için yazarlar tarafından geliştirilen ve Tektonik Araçlar olarak adlandırılan, koordinat dönüşümü, RINEX düzenleme, hız, gerinim ve odak mekanizma çizimi vb. işlemleri pratik olarak gerçekleştirmeye yarayan 
Python tabanlı çevirim içi bir servis geliştirilmiştir

(Resim 1).

\section{TEKTONIKK ARAÇLAR}

Anasayfa Nasıl Kullanılır? Teşekkürler Yardımcı Scriptler

\begin{tabular}{|c|c|c|c|}
\hline KML Üretme & GMT ile Çizim & Koordinat Dönüşümü & RINEX İşlemleri \\
\hline $\begin{array}{l}\text { (1) KML Üretme } \\
\text { (1) Meta KML Üretme }\end{array}$ & $\begin{array}{l}\text { ( Nokta Çizme } \\
\text { ( } \frac{\text { Hız Clizme }}{\text { Strain Çizme }} \\
\text { ( ) Odak Mekanizma Cizme }\end{array}$ & 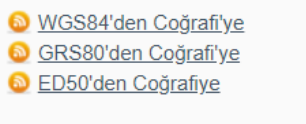 & $\begin{array}{l}\text { (1) Birleștirme } \\
\text { ( Saniye Dönüșümü } \\
\text { (a. Kalite Kontrol }\end{array}$ \\
\hline
\end{tabular}

Resim 1. Geliştirilen servise ait ekran görüntüsü

\section{Sistem altyapısı}

\subsection{Sunucu}

Geliştirilen çevirim içi servis için 2 core CPU, 4 GB Ram özelliklerinde ve Ubuntu 18.04 işletim sistemine sahip sunucu kullanılmaktadır.

\subsection{Python}

Python, ücretsiz, açık kaynak kodlu, nesne tabanlı, yorumlamalı, yüksek seviyeli ve çok geniş kütüphaneleri içeren bir programlama dili olup girintilere dayalı basit sözdizimi, dilin öğrenilmesini ve akılda kalmasını kolaylaştırır. Hollandalı bir programcı olan Guido Van Rossum tarafindan 1990'lı yıllarda geliştirilmiştir. Google, Dropbox vb. çok sayıda uluslararası kuruluş tarafından etkin olarak kullanılan Python dilinin bazı temel özellikleri:

- Hızlı program yazmayı, gömülü sistemlere etkin bir şekilde entegre olmayı sağlar.

- Platformdan bağımsızdır ve bu sayede Linux, Windows vb. tüm işletim sistemleri üzerinde çalışabilmektedir.

- Açık kaynak kodlu bir yazılımdır.

- Geniş ve işlevsel kütüphanelere sahiptir.

- Makine öğrenmesi vb. çalışmalarda etkin olarak kullanılmaktadır.

- Gelişmiş modülleri sayesinde (Scipy, Numpy vb.) bilimsel çalışmalarda kullanılmaktadır (Int Kyn. 1).

\subsection{Flask}

Flask, Python programlama diliyle yazılmış güçlü, esnek, bir web uygulama geliştiricisidir (framework). Diğer frameworklere göre (Django, Web2pay, Turbogears vb.) daha basit ve kolay anlaşılır bir yapıda olması nedeniyle çok sayıda kullanıcısı vardır. Microframework olan Flask, hızlı web uygulamaları geliştirmede oldukça büyük bir öneme sahiptir (İnt Kyn. 2).

\subsection{Generic Mapping Tools (GMT)}

Çoğunluğu yer, atmosfer ve okyanus bilimleriyle uğraşan disiplinler olmakla birlikte veri görselleştirmeye intiyaç duyulan tüm disiplinlerde yaygın olarak kullanılmaktadır. İlk olarak Prof. Paul Wessel ve Prof. Walter Smith tarafından 1988 yılında geliştirilmiştir. GMT açık kaynak programcılığı felsefesini temel alan, coğrafi verileri işleyen, filtreleyen, gridleyen ve bir harita projeksiyonuna değişik görselleştirme yöntemleriyle 2 ve 3 boyutlu olarak aktaran ve 30'dan fazla harita projeksiyonu desteğine sahip bir programdır. Komut satırından çalışması nedeniyle çok esnek bir yapıya sahiptir. Kullanım için bir ara yüze sahip olmaması nedeniyle profesyonel olmayan kullanıcılar açısından vakit alıcı olabilmektedir (Wessel et al. 2013, Int Kyn. 3).

\subsection{Translating Editing and Quality Check (TEQC)}


TEQC Dr. Lou Estey tarafından geliştirilmiş, RINEX veya BINEX formatında GPS, GLONASS, Galileo, SBAS, Beidou, QZSS ve IRNSS verileri üzerinde kalite kontrolü, birleştirme vb. çok sayıda işlemi yapmaya yarayan bir programdır (Estey and Meertens, 1999, Int Kyn. 4).

\subsection{Hypertext Markup Language (HTML)}

HTML yazı, video veya görsel öğelerin sayfa içerisine yerleştirilmesine ve istenildiği gibi konumlandırılmasını sağlayan bir işaretleme dilidir. Aynı zamanda hazırlanan sayfaların web tarayıcısında düzgün bir şekilde görülmesini sağlar. Hazırlanan kodlar web tarayıcıları tarafından anlaşılarak görsel web sayfalarına dönüştürülür. Bununla birlikte girilen web sitesi hakkında arama motorlarına bilgi verilmesini sağlar. Bir programlama dili değildir (İnt Kyn. 5).

\section{Sistem çalışma prensibi}

Sistem GNSS ile tektonik hareketlerin belirlenmesi sürecinde kullanıcıya 4 temel aşamada katkı sağlamaktadır. Bunlar:

- Mevcut RINEX verilerinin listelenmesi

- Noktaların Google Earth ortamına aktarılması

- Verilerin değerlendirmeye hazır hale getirilmesi

- Çıktıların görselleştirilmesi

olarak tanımlanabilir. Bu aşamalara ek olarak kullanıcının ihtiyaç duyabileceği yardımcı scriptler servis üzerinde "Yardımcı Scriptler" sayfasına listelenmiştir (RINEX veri listeleme, RINEX tarih düzeltme, I-file üretme (Gamit/GLOBK), dosya adı küçültme, Post Script (ps) dosyalarını PDF'e çevirme).

\subsection{Mevcut RINEX verilerinin listelenmesi}

Ağ planlaması öncesinde çalışma bölgesine ait eski verilerin temini daha doğru ve hassas sonuçlar, bütçe, arazi çalışması süresi vb. konularda avantaj sağlamaktadır. Bu aşamada kullanıcının temin edebileceği eski veri sayısı büyük önem arz etmektedir. Hiç veri olmayabileceği ya da çok az veri olabileceği gibi binlerce veri bulmakta mümkündür. Temin edilen verilerin konum bilgisi, ölçü süresi, nokta tesis tipi, anten yüksekliği, alıcı ve anten türü bilgilerine göre filtrelenmesi ve çalışma bölgesindeki konumlarına göre ağ planlamasında kullanılıp kullanılmayacağının belirlenmesi gerekmektedir.

Binlerce verinin sunucu tarafına taşınıp filtrelenmesi mümkün olmadığı için bu işlemi verilerin bulunduğu bilgisayar ortamında hızlı bir şekilde yapacak bir RINEX listeleme programı geliştirilmiştir. Kullanıcı "Yardımcı Scriptler" sayfasından indirdiği RINEX veri listeleme scriptini RINEX verilerinin bulunduğu ana klasörde çalıştırması durumunda tüm alt klasörlerde yer alan veriler nokta adı, x, y, z, alıcı türü, anten tipi, anten yüksekliği, ölçü tarihi, ölçü süresi, dosya yolu sıralamasıyla yeni oluşturulacak 'verilistesi.txt' dosyasında listelenecektir.

\subsection{Noktaların Google Earth Ortamına Aktarılması}

Listelenen verilerin Google Earth / HGM Küre üzerindeki dağılımını görebilmek için üretilen txt dosyasındaki $x, y$ ve $z$ sütunlarında yer alan koordinatların servis üzerinde yer alan "Koordinat Dönüşümü" sayfasında belirtilen şekilde coğrafi koordinatlara dönüştürülmesi gerekmektedir.

Sonraki aşamada ise txt dosyası servis üzerinde yer alan "Meta KML Üretme" sayfasına yüklenir ve tüm noktaların ve noktalara ait bilgilerin olduğu KML dosyası indirme bağlantısı yardımıyla indirilir. Indirilen dosya Google Earth ya da HGM Küre uygulaması ile açıldığında herhangi bir noktaya tıklanarak nokta ile ilgili tüm bilgiler görüntülenebilir (nokta adı, x, y, z, alıcı türü, anten tipi, anten yüksekliği, ölçü tarihi, ölçü süresi, dosya yolu).

\subsection{Verilerin Değerlendirmeye Hazır Hale Getirilmesi}

Kullanıcı ağ planlaması sonrası arazide GNSS gözlemlerini gerçekleştirdikten sonra eski ve yeni tüm verilerin değerlendirme için hazırlanması 
gerekmektedir. Bu noktada RINEX birleştirme, saniye dönüşümü ve kalite kontrolü işlemleri servis üzerinde yer alan "RINEX İşlemleri" kısmından yapılabilir.

\section{4 Çıktıların Görselleştirilmesi}

Değerlendirme sonrası nokta, hız, gerinim ve odak mekanizma çözümü parametreleri servis üzerinde yer alan "GMT ile Çizim" sayfasından görselleştirilebilir. Bu aşamada çıktıda yer alması istenilen bilgilere ait dosyaların belirtilen formatlarda (org, gmt, txt, dat) yüklenmesi gerekmektedir. Sadece nokta ya da nokta, gerinim ve odak mekanizma çözümü vb. olmak üzere çıktı görselinde olması istenilen dosyaların yüklenmesi yeterlidir. Dosya yükleme işleminden sonra renk, kalınlık, uzunluk, büyüklük ve ölçek bilgileri istenilen şekilde seçilir ve çizim işlemi yapılır. Yapılan çizim gereken/istenilen değişikliklerin yapılabilmesi için önce kullanıcıya ekranda gösterilir. Bu sayede kullanıcı son şeklini verene kadar herhangi bir indirme işlemi yapmak durumunda kalmaz. Üretilen çıktı kullanıcıya ps, pdf, jpg ve png olmak üzere yüksek çözünürlükte ve 4 farklı formatta sunulur.

\section{Uygulama}

RINEX verilerinin listelenmesi, koordinat dönüşümü ve Meta KML üretme fonksiyonlarını test etmek için düzensiz ve farklı klasör/alt klasörlerde bulunan 20 noktaya ait 100 RINEX dosyası seçilerek gereken işlemler belirtilen sırayla uygulanmıştır. Veri görselleştirme için (Aktuğ 2009)'da ve hız verisi olan noktalardan 29 tanesi seçilmiştir. (Çizelge 2) Gerinim verisi ise yine bu hızlar kullanılarak
Geodsuit v3.2 yazılımı ile üretilmiştir. Deprem odak çözümü için rastgele konum ve büyüklük tanımlanmıştır.

Çizelge 2. Görselleştirmede kullanılan hızlar (mm/yıl) (Aktuğ et al. 2009)

\begin{tabular}{|c|c|c|c|c|c|c|c|}
\hline Boylam & Enlem & Ve & Vn & $\mathrm{Se}$ & Sn & RHO & Nokta \\
\hline 28,01 & 38,96 & $-22,89$ & $-8,96$ & 0,77 & 0,74 & 0,1 & akhi \\
\hline 28,483 & 38,315 & $-22,61$ & $-13,18$ & 0,86 & 0,8 & 0,1 & alse \\
\hline 26,406 & 36,586 & $-14,23$ & $-30,03$ & 0,61 & 0,54 & 0,1 & astp \\
\hline 27,308 & 38,711 & $-17,44$ & $-14,74$ & 0,69 & 0,65 & 0,1 & bayo \\
\hline 27,423 & 37,032 & $-15,96$ & $-26,08$ & 0,6 & 0,52 & 0,1 & bodr \\
\hline 28,23 & 38,07 & $-21,41$ & $-13,97$ & 0,62 & 0,66 & 0,1 & byda \\
\hline 27,836 & 37,196 & $-17,58$ & $-24,98$ & 0,57 & 0,52 & 0,1 & camk \\
\hline 26,385 & 38,311 & $-18,32$ & $-22,88$ & 0,48 & 0,48 & 0,1 & ceil \\
\hline 27,96 & 37,63 & $-20,45$ & $-21,6$ & 0,67 & 0,69 & 0,1 & cinc \\
\hline 28,081 & 37 & $-2 C$ & -21 & 0,43 & 4 & 1 & cine \\
\hline 27,38 & o & -21 & -20 & 0,67 & 0,69 & 0,1 & $\mathrm{cmlk}$ \\
\hline 28,826 & 36,762 & $-15,44$ & $-20,07$ & 0,6 & 0,56 & 0,1 & dlmn \\
\hline 28,99 & 38,51 & $-22,64$ & $-7,49$ & 0,55 & 0,55 & 0,1 & esme \\
\hline 26,085 & 38,443 & $-19,07$ & $-22,96$ & 0,65 & 0,59 & 0,1 & hios \\
\hline 28,82 & 38,34 & $-24,12$ & $-10,71$ & 0,58 & 0,62 & 0,1 & hrdl \\
\hline 27,394 & 36,681 & $-11,85$ & $-29,9$ & 0,58 & 0,54 & 0,1 & knid \\
\hline 26,929 & 36,752 & -15 & $-26,53$ & 0,65 & 0,56 & 0,1 & kosi \\
\hline 28,74 & 38,57 & $-23,31$ & $-9,68$ & 0,64 & 0,64 & 0,1 & kula \\
\hline 27,963 & 36,772 & $-14,23$ & $-25,98$ & 0,53 & 0,48 & 0,1 & marm \\
\hline 26,72 & 38,43 & $-19,35$ & $-12,86$ & 1,01 & 1,01 & 0,1 & mnts \\
\hline 28,427 & 37,175 & $-17,91$ & $-20,94$ & 0,51 & 0,51 & 0,1 & mula \\
\hline 28 & 38,248 & $-20,62$ & $-12,62$ & 0,84 & 0,78 & 0,1 & odme \\
\hline 27,085 & 38,019 & $-20,01$ & $-19,68$ & 0,62 & 0,55 & 0,1 & ozde \\
\hline 26,989 & 37,78 & $-18,97$ & $-23,89$ & 0,63 & 0,55 & 0,1 & samo \\
\hline 27,486 & 37,818 & $-19,66$ & $-18,98$ & 0,82 & 0,78 & 0,1 & soke \\
\hline 28,58 & 37,58 & $-22,53$ & $-17,56$ & 0,59 & 0,62 & 0,1 & thrn \\
\hline 27,61 & 38,26 & $-22,15$ & $-17,16$ & 0,59 & 0,62 & 0,1 & uctp \\
\hline 26,74 & 38,38 & $-22,92$ & $-20,31$ & 0,67 & 0,75 & 0,1 & uris \\
\hline 26,79 & 38,74 & $-23,26$ & $-17,48$ & 0,77 & 0,92 & 0,1 & yenf \\
\hline
\end{tabular}

\subsection{Mevcut RINEX verilerinin listelenmesi}

RINEX dosyalarının bulunduğu ana klasörde listeleme programı çalıştırılarak alt klasörlerde yer alan ve farklı uzantılara sahip olan (RINEX, navigasyon, meteoroloji, txt, $x l s, d o c, p d f \mathrm{vb}$.) toplam 300 dosya içerisinden yalnızca RINEX gözlem dosyaları başarıyla listelenmiştir. (Resim 2) 


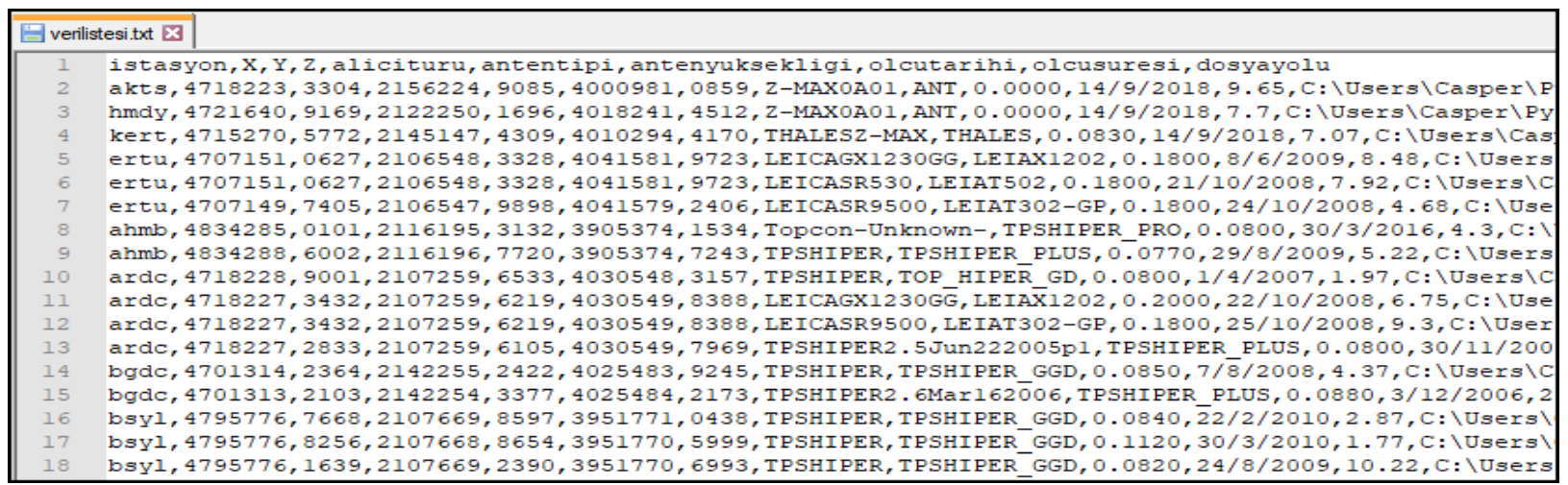

Resim 2. Listeleme programı ile listelenen veriler

\subsection{Noktaların Google Earth Ortamına AktarıIması}

Üretilen txt dosyasındaki $x, y$ ve $z$ sütunlarında yer alan Kartezyen Koordinatlar coğrafi koordinatlara servis üzerinden dönüştürülmüştür (Resim 3-4). Veri listesinin son hali servis üzerinden Meta KML dosyasına dönüştürülmüştür (Resim 5-6).

\begin{tabular}{|c|c|}
\hline - WGS84 $\rightarrow$ Cografi $\bigcirc$ GRS80 $\rightarrow$ Cografi & ED-50 $\rightarrow$ Cografi \\
\hline \multicolumn{2}{|l|}{ Girilen Veri Formatı:- } \\
\hline NoktaAdi, $X, Y, Z \odot X, Y, Z$ & \\
\hline 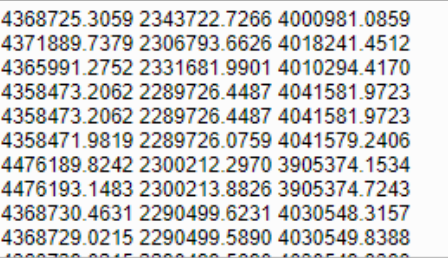 & \\
\hline
\end{tabular}

Resim 3. Koordinat Dönüşüm Ekranı

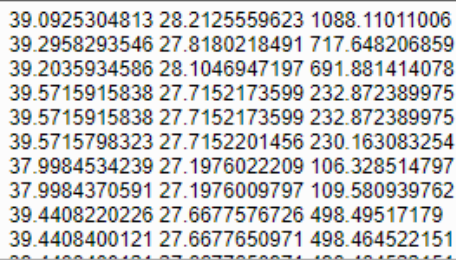

Resim 4. Dönüşmüş Koordinatlar

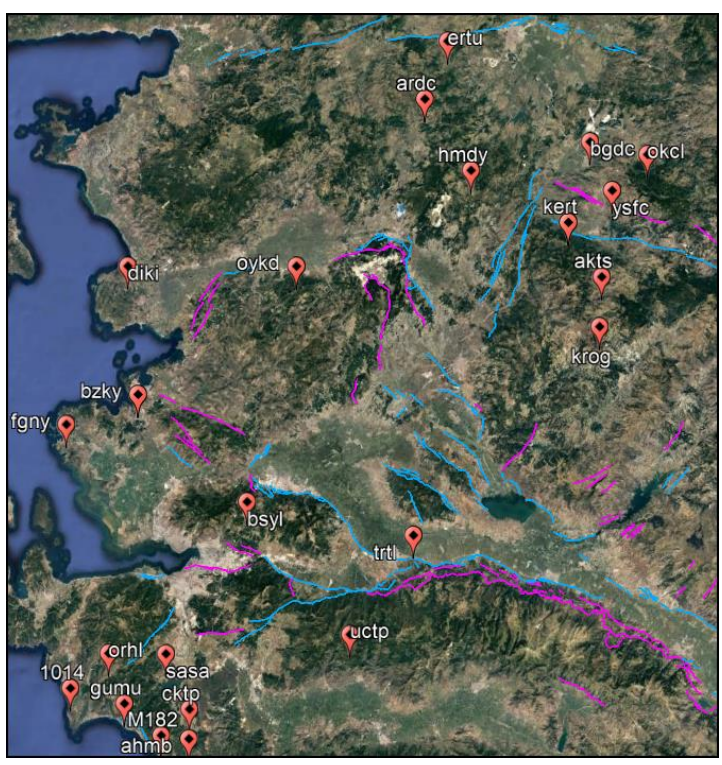

Resim 5. KML Ekran Görüntüsü

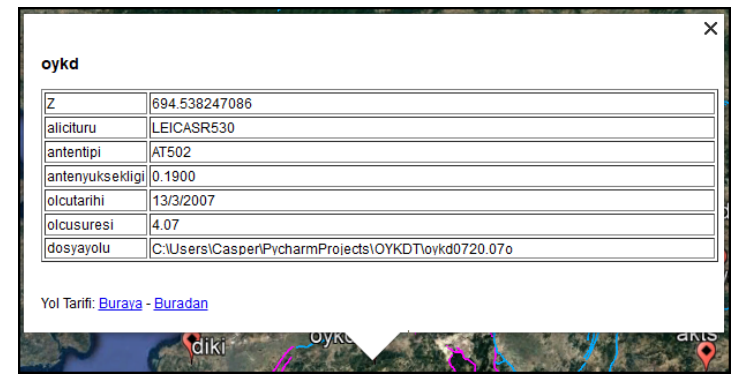

Resim 6. Noktalara ait bilgiler (Meta)

\subsection{Verilerin Değerlendirmeye Hazır Hale Getirilmesi}

Ağ planlaması yapıldıktan sonra RINEX verileri içerisinde ihtiyaç duyulanlar için birleştirme, saniye dönüşümü ve kalite kontrolü işlemleri yapılmıştır (Resim 7). 


\begin{tabular}{|c|c|c|}
\hline \multicolumn{3}{|c|}{ SANIYE DÖNÜŞŪMŪ } \\
\hline Rinex dosyası ( $\left({ }^{*} 0\right):$ & \multicolumn{2}{|c|}{ Dosya Seç akts2570.180 } \\
\hline \multicolumn{3}{|c|}{ Kaç Saniyeye Dönüşecek: 30} \\
\hline \multicolumn{3}{|c|}{ KALITE KONTROLÜ } \\
\hline Rinex dosyası (. $\left.{ }^{*} 0\right):$ & Dosya Seç & akts 2570.180 \\
\hline \multicolumn{3}{|c|}{ RINEX BIRLEŞTIRME } \\
\hline \multirow{2}{*}{$\begin{array}{l}\text { 1. Rinex dosyası }\left({ }^{*} 0\right): \\
\text { 2. Rinex dosyası }\left({ }^{*} 0\right)\end{array}$} & Dosya Seç & akts 2570.180 \\
\hline & Dosya Seç & akts 2571.180 \\
\hline
\end{tabular}

Resim 7. RINEX İşlem Listesi

\section{4 Çıktıların Görselleştirilmesi}

Seçilen noktalara ait hızlar ve bu hızlardan üretilen gerinim alanları servis üzerinden görselleştirilmiştir (Resim 8, Şekil 1, Şekil 2, Şekil 3). Görselleştirme için kullanılan enlem boylam sınırları girdi dosyalarından okunmakta olup $\pm 0.3 \stackrel{0}{\text { geniş }}$ alınmaktadır.

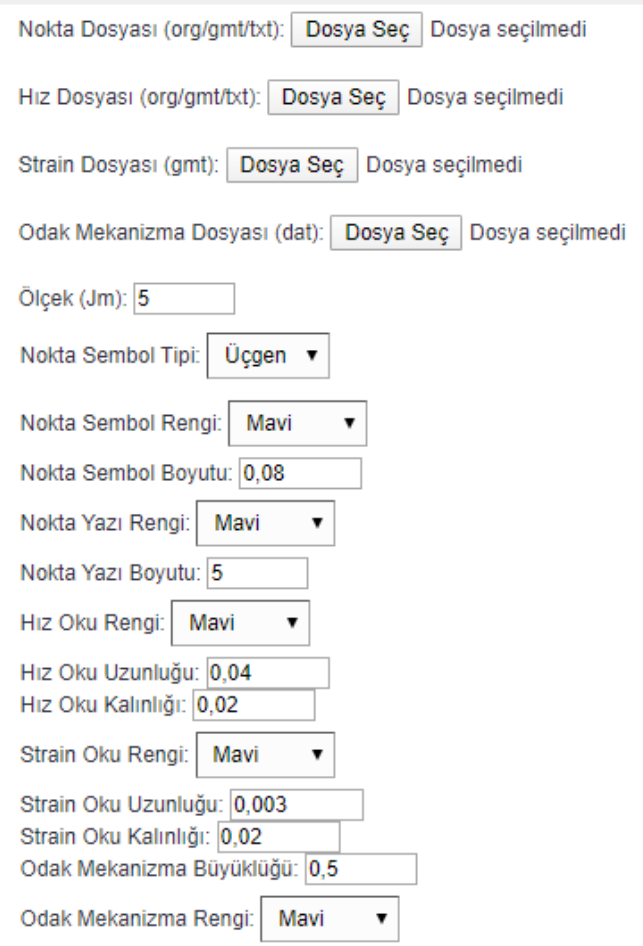

Resim 8. Veri görselleştirme sayfası ekran görüntüsü

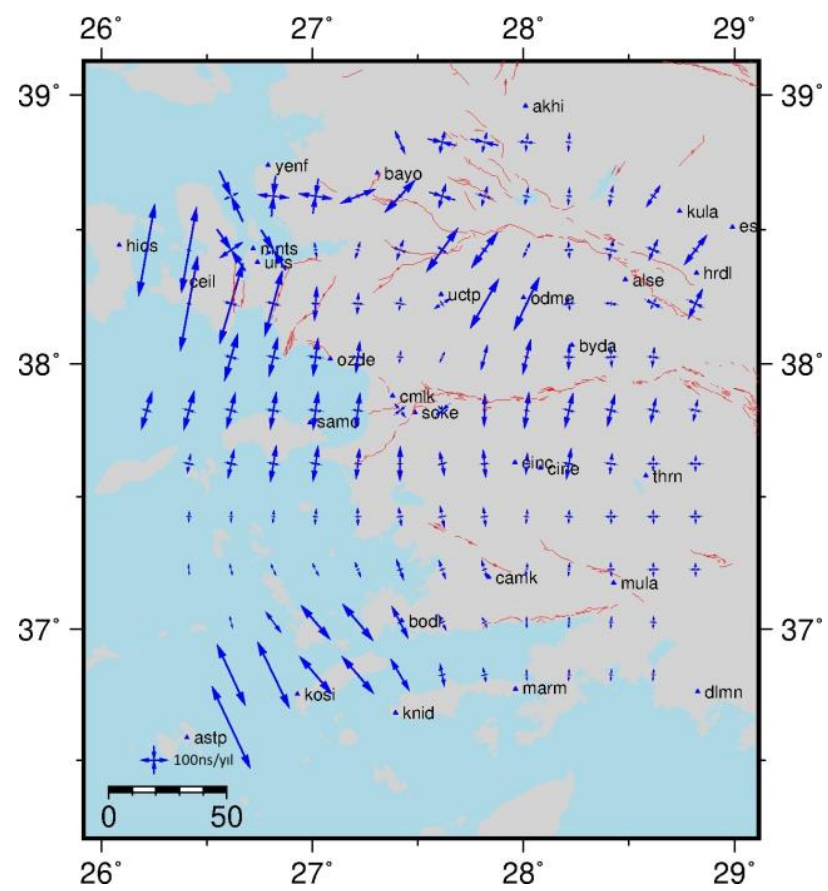

Şekil 1. Gerinim çizimi

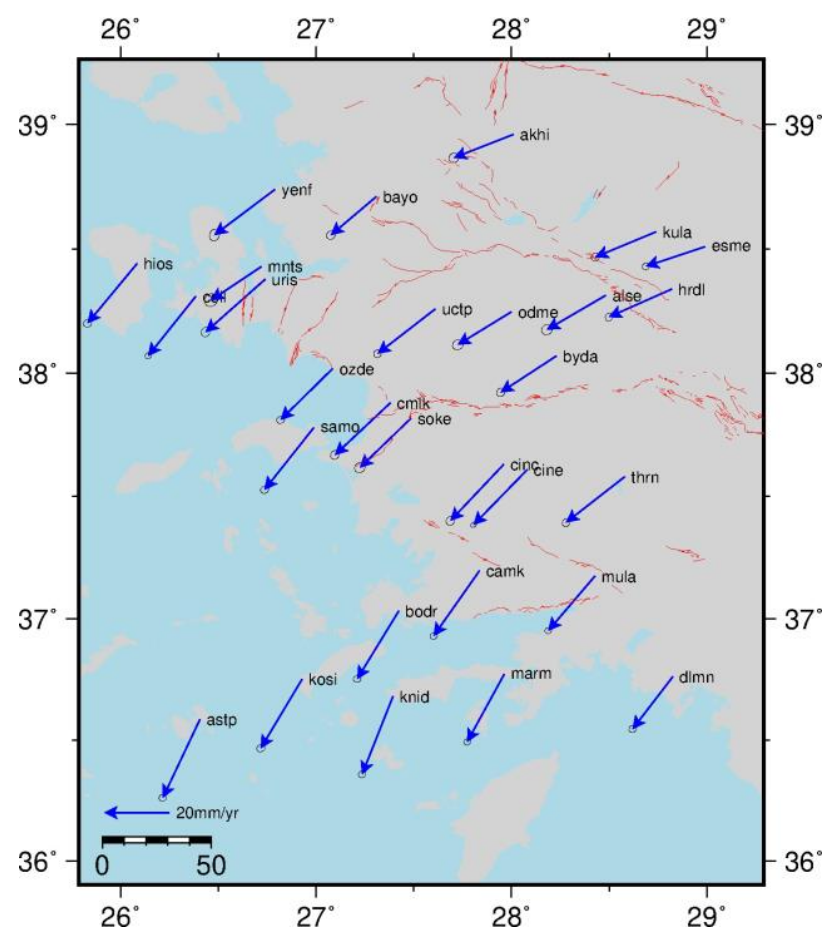

Şekil 2. Hız çizimi 


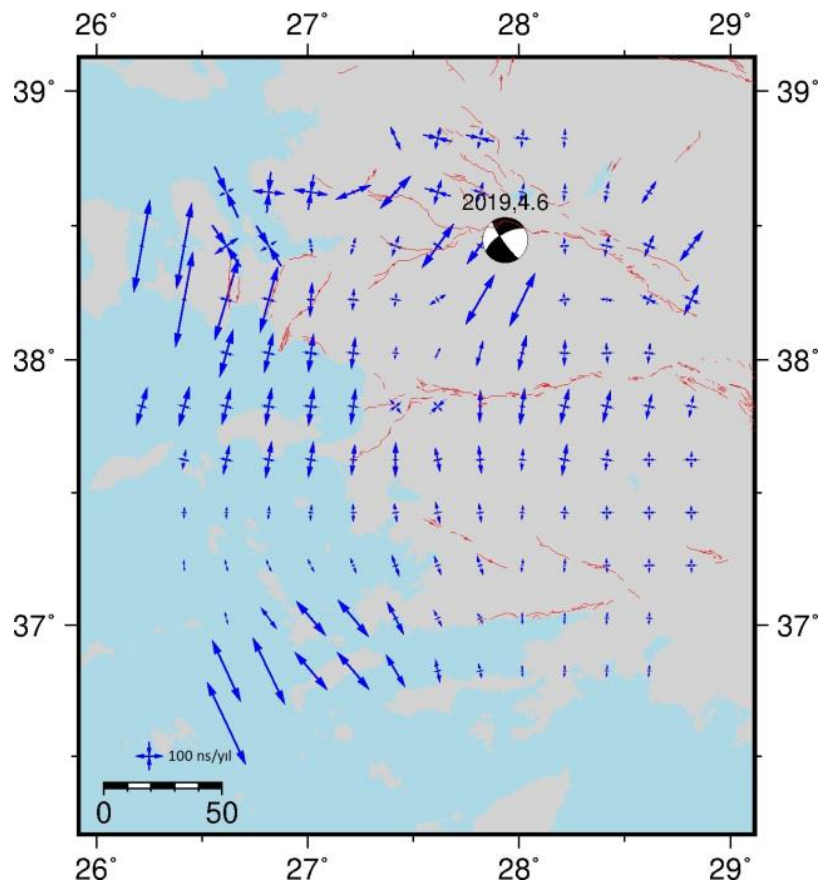

Şekil 3. Nokta, gerinim ve odak mekanizma çizimi

\section{Sonuçlar}

GNSS teknolojisinin gelişmesiyle birlikte uydular yardımı ile konum belirlemede daha doğru ve hassas konum bilgisi elde etmek mümkün hale gelmiştir. Bu durum konum bilgisini kullanan disiplinlerde gerçekleştirilen çalışmaları çeşitlendirmiştir. Konum bilgisi üreten, bu bilgiyi çeşitli alanlarda kullanan ve ihtiyaç duyan disiplinlere sunan Haritacılık disiplini de bu gelişmelere paralel olarak gelişmektedir. GNSS ölçüleri ile birlikte tektonik hareketleri belirlemek buna örnek olarak verilebilir.

GNSS ölçüleri ile tektonik hareketleri belirleme süreci genel olarak ağ planlaması, GNSS gözlemleri, verilerin değerlendirilmesi ve sonuçların yorumlanması aşamalarından oluşmaktadır. Bu aşamalar gerçekleştirilirken çok sayıda ara işlemin manuel olarak yapılması ve yardımcı programların kullanılması gerekmektedir. Bu durum süreci uzatmakla birlikte hatalara neden olabilmektedir.

Bu çalışma kapsamında ilgili alanlarda çalışan tüm araştırmacıların herhangi bir ara program ya da yazılım dili bilmeksizin bahsedilen işlemleri pratik olarak gerçekleştirmesi için Python tabanlı çevirim içi bir servis geliştirilmiştir. Çalışma kapsamında geliştirilen servise ek olarak kullanıcıların Tektonik Uygulama sürecinde karşılaşabilecekleri mikro sorunlar için yardımcı scriptler geliştirilmiş ve servis web sitesi üzerinden sunulmuştur. Geliştirilen servis bir amaca yönelik olarak gerçek verilerle birlikte test edilmiş ve elde edilen tüm sonuçlar paylaşılmıştır.

Sonuçlar değerlendirildiğinde geliştirilen servisin sorunsuz çalıştı̆̆ı ve tektonik uygulama sürecini önemli ölçüde hızlandırdığı değerlendirilmiştir. Servis 193.255.49.96 IP adresinden ücretsiz olarak ilgili alanlardaki tüm araştırmacıların kullanımına açıktır. Kullanıcılar tarafından yapılan geribildirimlerle birlikte servisin geliştirilmesi planlanmaktadır.

\section{Teşekkür}

Altyapı için Afyon Kocatepe Üniversitesi Bilgi İşlem Daire Başkanlığı'na, kullanılan araçlar için Python, Flask, Gamit/GLOBK, GMT, HTML geliştiricilerine teşekkür ederiz.

\section{Kaynaklar}

Aktuğ, B., Nocquet, J.M., Cingöz, A., Parsons, B., Erkan, Y., England, P., Lenk, O., Gürdal, M.A., Kılıçoğlu, A., Akdeniz, H., and Tekgül, A., 2009. Deformation of western Turkey from a combination of permanent and campaign GPS data: Limits to block-like behaviour. Journal of Geophysical Research, 114, B10404, doi: 10.1029/2008JB006000.

Eckl, M.C., R. Snay, T. Soler, M.W. Cline \& G.L. Mader, 2001. Accuracy Of GPS-Derived Relative Positions As A Function Of Interstation Distance And ObservingSession Duration. Journal Of Geodesy, 75 (12), 633640.

Essey, L.H., ve Meertens C.M., 1999. TEQC: The MultiPurpose Toolkit for GPS/GLONASS Data, GPS Solutions, John Wiley \& Sons, Inc., 3 (1), pp. 42-49.

Özener, H., Doğru, A., 2009. Jeodezik ve Sismik verilerden Yararlanarak Kabuk Deformasyonu Alanının Belirlenmesi. Jeodezi, Jeoinformasyon ve Arazi Yönetimi Dergisi, 2009/3 Özel Sayı 96-102.

Solak, H. İ., 2015, GNSS Hızları ile Güneybatı Anadolu'daki Gerinim Alanlarının Zamansal Değişimi, 
Yüksek Lisans Tezi, Afyon Kocatepe Üniversitesi, Fen Bilimleri Enstitüsü, Afyon, 95.

Tiryakioğlu, I.,, Dereli, M.A., Erdoğan, S., Gülal, E., "Tektonik Hareketlerin Belirlenmesine Yönelik Ölçü Kampanyalarında GNSS Gözlem Sayı ve Sürelerinin Konum Doğruluğuna Olan Etkilerinin Araştırılması". Harita Teknolojileri Elektronik Dergisi, 2010, 2 (2) 3238.

Tiryakioglu I., Gulal E., Solak H.I., Ozkaymak C. (2018) Crustal Deformation Modelling by GNSS Measurements: Southwestern Anatolia, Turkey. In: Kallel A., Ksibi M., Ben Dhia H., Khélifi N. (eds) Recent Advances in Environmental Science from the EuroMediterranean and Surrounding Regions. EMCEI 2017. Advances in Science, Technology \& Innovation (IEREK Interdisciplinary Series for Sustainable Development).

Yavaşoğlu, H., 2003, Kuzey Anadolu Fayının Orta Bölümünün Kinematiğinin 2001 ve 2002 GPS Ölçmeleri ile Belirlenmesi, Yüksek Lisans Tezi, I.T.Ü. Fen Bilimleri Enstitüsü, İstanbul, 64.

Wessel, P., W. H. F. Smith, R. Scharroo, J. Luis, and F. Wobbe, Generic Mapping Tools: Improved Version Released, EOS Trans. AGU, 94 (45), p. 409-410, 2013. doi:10.1002/2013E0450001.

\section{internet kaynakları}

1- https://python.org

2- https://palletsprojects.com/p/flask/

3- http://www.atag.itu.edu.tr/GMTtr/

4-https://www.unavco.org/software/data-

processing/teqc/teqc.html

5- https://www.w3schools.com/html/ 